\title{
Visual Response Properties and Visuotopic Representation in the Newborn Monkey Superior Colliculus
}

\author{
M. T. WALLACE, J. G. McHAFFIE, AND B. E. STEIN \\ Department of Neurobiology and Anatomy, Bowman Gray School of Medicine/Wake Forest University, Winston-Salem, \\ North Carolina 27157
}

\begin{abstract}
Wallace M. T., J. G. McHaffie, and B. E. Stein. Visual response properties and visuotopic representation in the newborn monkey superior colliculus. J. Neurophysiol. 78: 2732-2741, 1997. Visually responsive neurons were recorded in the superior colliculus (SC) of the newborn rhesus monkey. The receptive fields of these neurons were larger than those in the adult, but already were organized into a well-ordered map of visual space that was very much like that seen in mature animals. This included a marked expansion of the representation of the central $10^{\circ}$ of the visual field and a systematic foveal to peripheral increase in receptive field size. Although newborn SC neurons had longer response latencies than did their adult counterparts, they responded vigorously to visual stimuli and exhibited many visual response properties that are characteristic of the adult. These included surround inhibition, withinfield spatial summation, within-field spatial inhibition, binocularity, and an adult-like ocular dominance distribution. As in the adult, SC neurons in the newborn preferred a moving visual stimulus and had adult-like selectivities for stimulus speed. The developmentally advanced state of the functional circuitry of the newborn monkey SC contrasts with the comparative immaturity of neurons in its visual cortex. It also contrasts with observations on the state of maturation of the newborn SC in other developmental models (e.g., cat). The observation that extensive visual experience is not necessary for the development of many adult-like SC response properties in the monkey SC may help explain the substantial visual capabilities shown by primates soon after birth.
\end{abstract}

INTRODUCTION

Altricial animals such as rodents, lagamorphs, and carnivores are born relatively helpless. They are blind at birth, having fused eyelids and a visual system that is incompletely differentiated. In such species, the peripheral and central visual apparatus undergo substantial maturation during a protracted postnatal period in which visual and visuomotor functions develop as the animal interacts with its environment (Grobstein and Chow 1976; Mitchell and Timney 1984; Movshon and Van Sluyters 1981; Sherman and Spear 1982; Stein and Meredith 1991; Tees 1976).

More precocial animals, such as primates, are also comparatively helpless at birth. However, the primate visual system undergoes substantially more prenatal maturation, and although it has not yet achieved its adult state (Boothe et al. 1985; Kiorpes and Kiper 1996; Van Sluyters et al. 1990), its development is comparatively advanced at birth (Des Rosiers et al. 1978; Horton and Hocking 1996; Hubel et al. 1977; LeVay et al. 1980; Purves and LaMantia 1993; Rakic 1977). The primate is born with its eyes open, and the optical properties of the eye allow for the formation of a clear image on the retina (Williams and Boothe 1981). Furthermore, the primate retina is already transmitting visual information to the brain by the time of birth (Blakemore and Vital-Durand 1981a,b; Wiesel and Hubel 1974).

Although it is not at all clear what the newborn primate makes of these early visual inputs, they do evoke overt behaviors. Thus newborn primates fixate on "interesting', visual stimuli and move their eyes to follow them (Boothe et al. 1982; Mendelson 1982). Because such visual functions are known to involve the superior colliculus (SC) in adults (Schiller and Koerner 1971; Schiller and Stryker 1972; Sparks 1986; Sprague and Meikle 1965; Stein and Meredith 1991; Wurtz and Albano 1980), it can be argued that SC circuits are sufficiently mature at birth to sustain some fundamental visual behaviors. Unfortunately, there is very little direct evidence regarding the functional state of the newborn primate SC. The present experiments were initiated to examine the visual responsiveness of individual neurons in the $\mathrm{SC}$ of the newborn rhesus monkey, Macaca mulatta. The initial objectives of this study were to determine whether these neurons have well-defined receptive fields, and if so, whether they, like their adult counterparts, are organized into a functional map of visual space. In addition, it was of interest to compare the relative maturity of the receptive field properties of SC neurons in the newborn and the adult. Last, it was of interest to determine whether SC neurons representing temporal visual space were maturationally advanced, a finding that might help explain the preferential reactions of human infants to targets in these regions of visual space (Lewis and Maurer 1992).

\section{METHODS}

\section{General procedures}

Both newborn (4-12 $\mathrm{h}$ postpartum; $n=2)$ and adult $(n=$ 3 ) rhesus monkeys were prepared for acute electrophysiological recording. Unless otherwise noted, the methods used were identical for both groups. Anesthesia was induced with a combination of ketamine hydrochloride $(5-10 \mathrm{mg} / \mathrm{kg} \mathrm{im})$ and acepromazine maleate $(0.1-0.2 \mathrm{mg} / \mathrm{kg} \mathrm{im})$. Animals were fixed in a Kopf headholder, the trachea was intubated, and surgical anesthesia was maintained with isoflurane $(1-4 \%)$. A craniotomy was made to provide access to the SC, and a recording well/head-holding device was attached to the skull to hold the animal during recording without the obstructions imposed by the stereotaxic frame (McHaffie and Stein 1983). After surgery, animals were respired artificially and paralyzed ( $1 \mathrm{mg} / \mathrm{kg}$ pancuronium bromide iv). The femoral vein was cannulated, and a continuous infusion of fluids (lactated Ringer; $2-10 \mathrm{ml} / \mathrm{h}$ ) and paralytic (pancuronium bromide; $0.2-0.4$ $\mathrm{mg} \cdot \mathrm{kg}^{-1} \cdot \mathrm{h}^{-1}$ ) was administered. In some animals, experimental 
anesthesia was maintained with ketamine hydrochloride (2-8 $\left.\mathrm{mg} \cdot \mathrm{kg}^{-1} \cdot \mathrm{h}^{-1} \mathrm{iv}\right)$. In others, inhalation isofluorane $(0.5-1.0 \%)$ was used. No difference was noted in the results obtained using either anesthetic, hence the data have been pooled and are analyzed as a single population. Expiratory $\mathrm{CO}_{2}$ was monitored and kept between 3.5 and $4.5 \%$, and body temperature was maintained at $37-38^{\circ} \mathrm{C}$ by means of a circulating hot water pad. Adequate levels of anesthesia were determined using standard reflex and recovery criteria ( see Wallace et al. 1996). The pupils were dilated with a $1 \%$ atropine sulfate solution, and the eyes were fitted with contact

NEWBORN
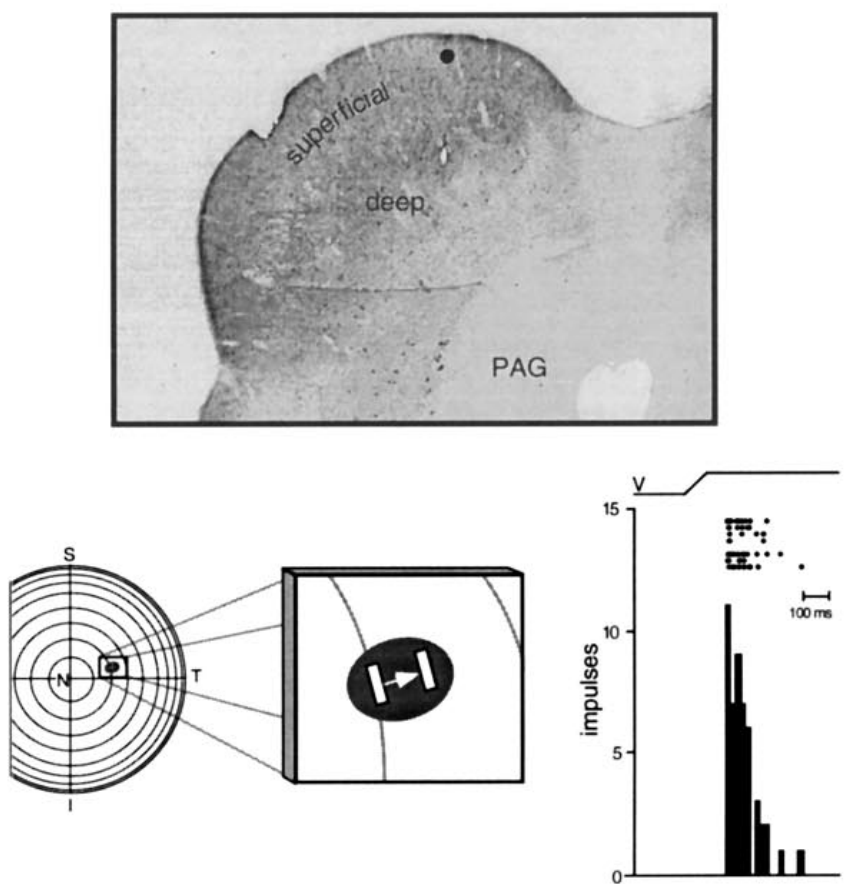

ADULT
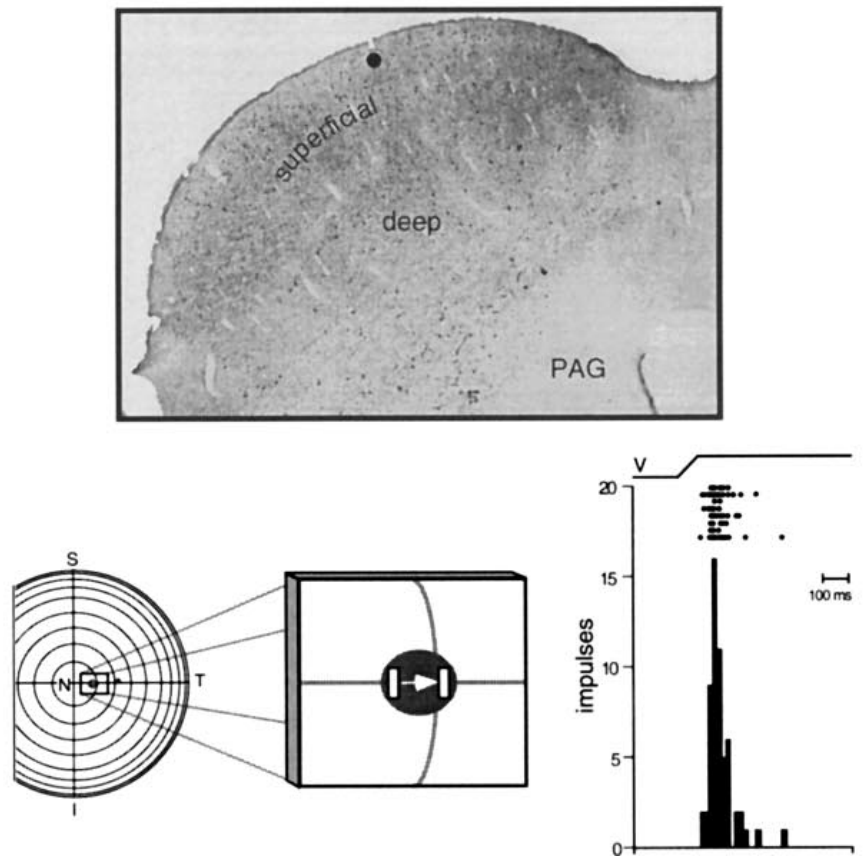

lenses to prevent corneal drying and to correct for refractive errors. The optic disks were projected onto a translucent $91 \mathrm{~cm}$ diameter Plexiglas hemisphere placed in front of the animal.

\section{Recording and sensory stimuli}

The electrode was advanced manually to the surface of the SC with a micromanipulator. On arrival at the surface of the SC, as determined by the appearance of characteristic multiunit visual activity, the electrode was advanced in small $(10-15 \mu \mathrm{m})$ steps by means of a hydraulic microdrive. Although deep layer neurons were recorded, unless otherwise stated, all observations in this report relate to superficial layer visually responsive neurons. Single- and multiunit neural discharges were recorded using paryleneinsulated tungsten microelectrodes (1.5-4.0 M $\Omega$; Frederick Haer). Amplified discharges were routed to an oscilloscope and audiomonitor, as well as to a computer for subsequent off-line analysis (see below).

Visually elicited responses were sought using both moving and stationary flashed stimuli that were projected onto the Plexiglas hemisphere. Once a visually responsive neuron was isolated, its location (i.e., depth) was noted, and its receptive field was mapped manually using a pantoscope with which bars and spots of light could be projected directly onto the translucent hemisphere. The borders of each receptive field were determined by moving the optimum visual stimulus from the periphery inward from all directions until an enclosed responsive area was delimited. All receptive fields were later plotted on standardized representations of visual space (Meredith and Stein 1990).

The neuron then was analyzed qualitatively to make an initial determination of its velocity selectivity, direction selectivity, ocular dominance, preference for moving versus stationary stimuli, etc. Once this initial assessment was completed, a systematic quantitative analysis of these properties was conducted using a battery of computer-controlled visual stimuli. Typically, responses were analyzed using 8-16 repetitions of a given stimulus or stimulus condition. Stimuli were generated from a high-intensity Prado projector equipped with diaphragms whereby the shape and size of the stimulus were controlled. Bars and spots of light (luminance 53 $\mathrm{cd} / \mathrm{m}^{2}$ against a background of $2.7 \mathrm{~cd} / \mathrm{m}^{2}$ ) were projected through a rotating prism and reflected from a galvanometer-driven mirror onto the translucent screen. Using this system, stimulus amplitude could be varied from 1 to $90^{\circ}$ and stimulus velocity could be varied from $<3$ to $>500^{\circ} / \mathrm{s}$. Stimuli could be moved in all directions across the receptive field. An electronic shutter was used to present stationary flashed stimuli within and outside the receptive field. Response latency was determined using optimally effective stimuli, and mean latency was calculated on the basis of the response to 10 stimulus repetitions.

For purposes of classification, neurons were grouped into those preferring slow $\left(<10^{\circ} / \mathrm{s}\right)$, intermediate $\left(10-100^{\circ} / \mathrm{s}\right)$, or fast

FIG. 1. Vigorous visual responses characterize superficial superior colliculus (SC) neurons in newborn and adult animals. Location of a representative newborn (top) and adult (bottom) neuron (both isolated in stratum griseum superficiale) whose responses are illustrated here are indicated $(\bullet)$ on the photomicrographs of coronal sections. Each neuron's receptive field is depicted on a standardized representation of visual space in which each concentric circle represents $10^{\circ}$. Inset: magnification of the receptive fields and illustrations of the stimulus: a bar of light moving at $50^{\circ} / \mathrm{s}$ in the direction of the arrow. Right: rasters and histograms illustrate neuronal responses to 8 stimulus repetitions. Visual stimulus motion (V) is depicted by the electronic trace (i.e., ramp) at the top of each raster. Each dot in the raster represents a single action potential, and each row of dots the response to a single trial. Trials are ordered from bottom to top. Histogram binwidth $=10 \mathrm{~ms}$. S, superior; $\mathrm{I}$, inferior; $\mathrm{N}$, nasal; $\mathrm{T}$, temporal. Conventions and abbreviations are followed in subsequent figures. 
$\left(>100^{\circ} / \mathrm{s}\right)$ stimulus speeds. Alternatively, some neurons responded almost equally well (variation of $<20 \%$ ) to stimuli moving at all tested speeds, and were categorized as broadly tuned. Direction selectivity was defined as exhibiting a twofold difference in the mean response between the "best'" and "null" directions of stimulus movement. Neurons were grouped on the basis of their ocular dominance using the classification system of Hubel and Wiesel (1968). Within-field spatial summation and inhibition were assessed by increasing stimulus diameter systematically as a percentage of receptive field size (i.e., 10, 30, 50, 70, and 90\%). Surround inhibition was determined using bars of light that extended beyond the excitatory border of the receptive field, as well as by the concurrent presentation of two stimuli, one inside and the other outside the receptive field.

\section{Statistical comparisons}

For purposes of comparison, data in the newborn and the adult was both pooled (i.e., entire newborn and adult populations) and divided on the basis of position in the SC (e.g., neurons with receptive fields in the central $10^{\circ}$, neurons with receptive fields from 10 to $30^{\circ}$, etc.). Neuronal responses to changing stimulus conditions (e.g., stimulus speed) were compared using $t$-tests, and response properties between populations were compared using $\chi^{2}$ analysis. For plots of receptive field area as a function of receptive field eccentricity (determined to be the geometric center of the receptive field), the data were transformed into a log-log representation, and the slopes of the adult and newborn lines were compared using a $F$ test.

\section{Lesions, histology, and euthanasia}

To examine the visuotopic organization of the superficial SC, closely spaced $(0.25-0.5 \mathrm{~mm})$ electrode penetrations were made along the AP and ML axes. In each penetration, electrolytic lesions were made by passing cathodal current $(5-10 \mu \mathrm{A}$ for 5-15 s) through the recording electrode, thereby enabling the trajectory of the penetration as well as the location of recorded neurons to be reconstructed. At the end of the experiment, the animal was anesthetized deeply with pentobarbital sodium ( $100 \mathrm{mg} / \mathrm{kg}$ iv $)$ and perfused transcardially with physiological saline followed by $4 \%$ paraformaldehyde and $0.1 \%$ glutaraldehyde. The tissue was cut on a Vibratome and processed by standard histological methods to determine the locations of recorded neurons (Wallace et al. 1996).

\section{RESULTS}

In both the newborn and the adult monkey, robust visually evoked responses were recorded as the electrode entered the SC. In all electrode penetrations, single and multiunit visual responses were elicited readily in the two most superficial layers of the SC, stratum zonale and stratum griseum superficiale. The responses of these neurons to a moving visual stimulus were very similar at these two different developmental stages (though neurons in the newborn tended to habituate more strongly and rapidly to repeated stimulus presentations ). Representative examples of these responses are shown in Fig. 1. The degree of visually evoked activity and the incidence of visually responsive neurons decreased as the electrode passed into the deepest portions of the superficial layers (deep stratum opticum). Electrode penetrations of similar length, position and trajectory yielded comparable numbers of visually responsive neurons in newborns and
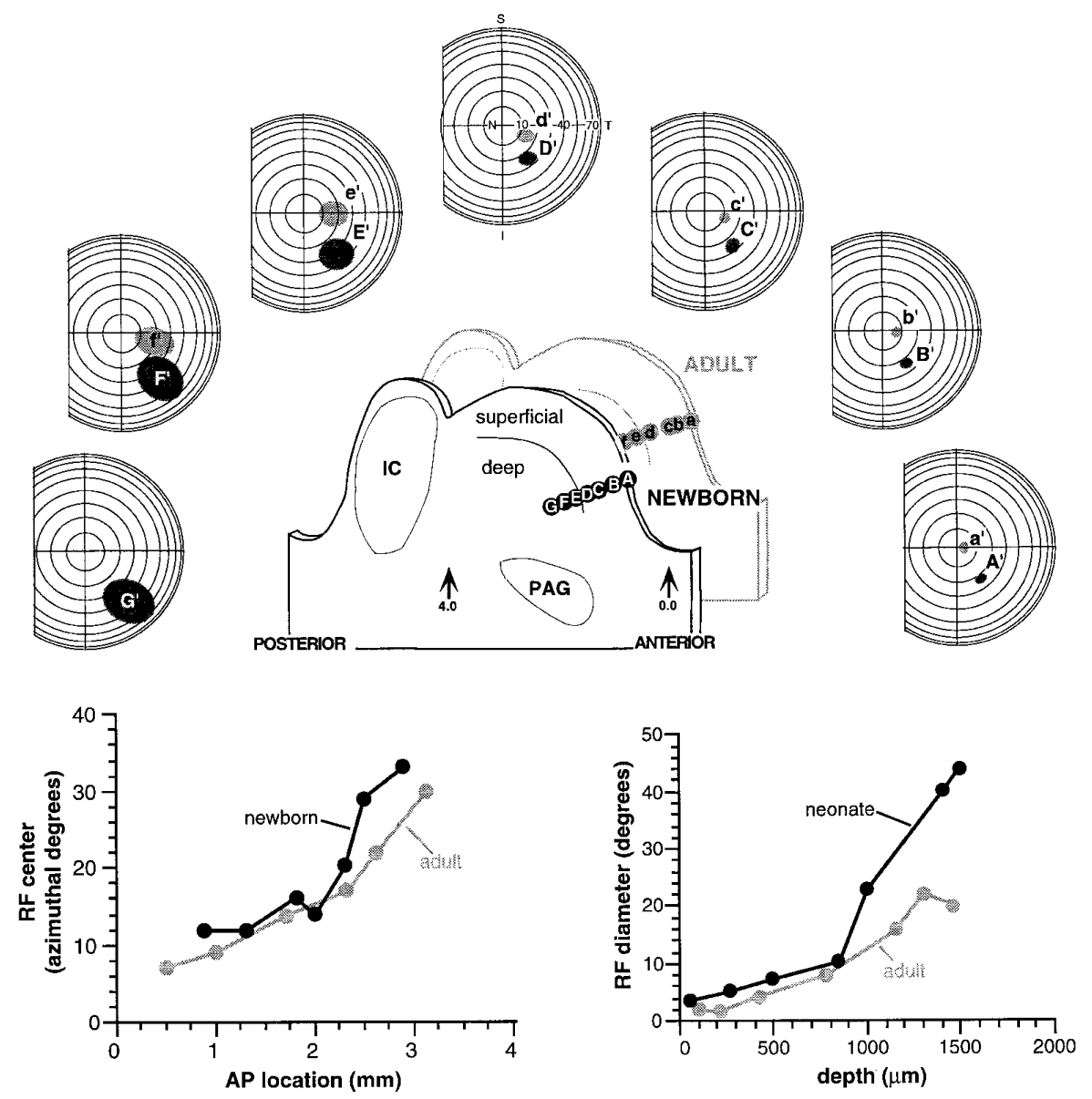

FIG. 2. Visual receptive fields shift systematically with neuronal location in the SC. Center: schematics illustrating representative electrode penetrations reconstructed and plotted onto parasagittal sections of the newborn and adult SC. Lettered circles represent sites at which visually responsive neurons were recorded. These letters also correspond to the letters demarking receptive fields on the representations of visual space (e.g., site A has receptive field $\mathrm{A}^{\prime}$, etc.). In both examples, note the systematic foveal-toperipheral shift in receptive fields as the electrode moves rostral to caudal, as well as the substantial increase in receptive field size after the electrode enters the deep layers of the SC (e.g., $\mathrm{e}^{\prime}, \mathrm{f}^{\prime}, \mathrm{E}^{\prime}, \mathrm{F}^{\prime}$, and $\mathrm{G}^{\prime}$ ). Bottom: plots of the increasing eccentricity of each neuron's receptive field center as a function of its anteriorposterior location (left), and the increase in receptive field size as a function of neuronal depth in the SC (right). On the parasagittal section, 0.0 and 4.0 represent the rostral and caudal poles of the SC, respectively. PAG, periaqueductal gray; IC, inferior colliculus. 
adults. A total of 116 visually responsive single units in the superficial layers were examined: 55 of these were in the newborn and 61 were in the adult.

\section{Visual topography in the newborn primate SC}

As in the adult, visually responsive neurons in the SC of the newborn had well-defined receptive fields that were organized into a topographic representation of visual space. Thus neighboring neurons had receptive fields representing overlapping regions of visual space. This was evident not only when the electrode was moved from place to place across the surface of the SC but also along the course of individual electrode penetrations. For example, note in Fig. 2 the systematic shift in receptive fields from foveal to peripheral as the electrode was moved through the SC along a rostral-to-caudal trajectory.

When the electrode passed into the deeper layers of the SC ( stratum griseum intermediale and below), visual, nonvisual (i.e., auditory, somatosensory), and multisensory (e.g., visual-auditory, visual-somatosensory, etc.) neurons were encountered. Although the receptive fields of visually responsive neurons in the deep layers were typically much larger than those in the superficial layers, they exhibited a similar topographic organization (Fig. 2).

To examine the topography of the superficial layer representation more closely, systematically spaced electrode penetrations were made in newborns and adults (Fig. 3). In both populations, neurons in the rostral SC had comparatively small receptive fields located in foveal regions of contralateral visual space (in only 2 neurons, 1 in the newborn and 1 in the adult, did the receptive field extend slightly into the ipsilateral visual hemifield). As more caudal locations were sampled, the receptive fields became larger and moved progressively toward more temporal regions of visual space (Figs. 2 and 3). Similarly, neurons at medial sites had receptive fields in superior space, and more lateral sites had progressively more inferior receptive fields. In both the newborn and the adult, a significant magnification of foveal and perifoveal space was seen in the rostral SC, so that approximately the rostral half of the SC was dedicated to visual space within $10^{\circ}$ of the vertical meridian (Fig. 3).

\section{Receptive field sizes and latencies}

Despite these similarities in receptive field organization, neurons in the newborn primate SC were not yet physiologically mature. Taken as a whole, the population of receptive fields of SC neurons in the newborn were significantly larger $(31 \% ; P<0.05)$ than those found in the adult. Although this difference appeared to be greatest near the fovea (Fig. 4), a comparison of receptive field sizes in the central $10^{\circ}$ failed to reach statistical significance. Trend analysis revealed the rate of growth of receptive fields with increasing eccentricity to be the same for the newborn and the adult (Fig. 4).

The average response latencies to the brightest flashed stimuli $\left(53 \mathrm{~cd} / \mathrm{m}^{2}\right)$ were also significantly $(P<0.01)$ longer in newborns $(159.9 \pm 36.5 \mathrm{~ms}$; mean $\pm \mathrm{SD})$ than in adults $(87.5 \pm 14.6 \mathrm{~ms})$. This was true despite the fact that the shortest response latency in the newborn was comparable with the shortest response latency in the adult $(\sim 60 \mathrm{~ms})$.

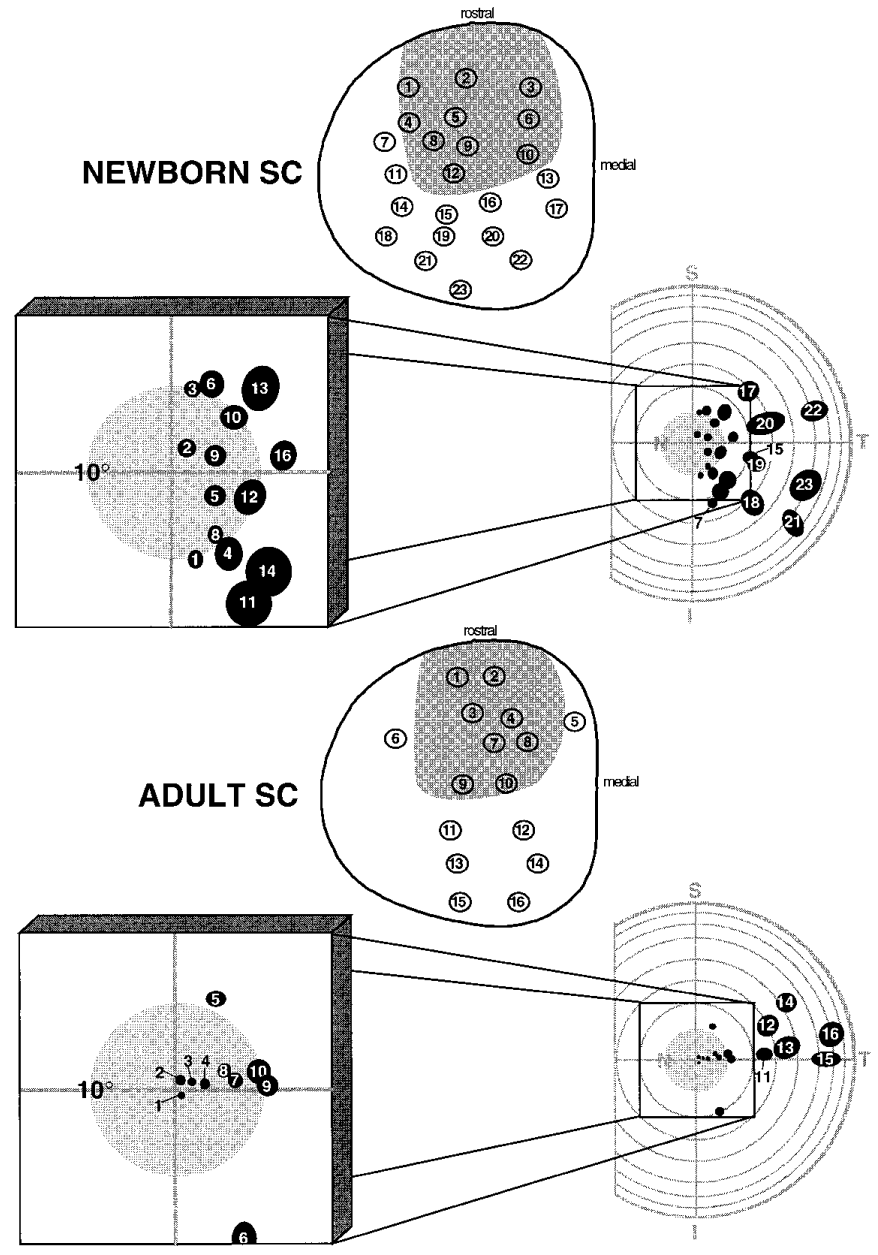

FIG. 3. SC in both newborns and adults is ordered visuotopically. Electrode penetrations are represented on the schematics of the dorsal surface of the SC with each numbered circle corresponding to a single electrode penetration. Receptive fields at each location are plotted and numbered correspondingly on the representations of visual space (right). Insets: receptive fields in foveal and perifoveal space, with the central $10^{\circ}$ indicated by shading. Shaded areas on the dorsal schematics of the SC show the corresponding location of the representation of the central $10^{\circ}$ in the SC. Note the similar magnifications of the central visual space in the neonate and adult, as well as the similar shifts in receptive field locations with position in the SC.

In large measure, the difference between the populations was attributable to the fact that adult latencies only rarely exceeded $120 \mathrm{~ms}$, whereas a substantial number of neurons in the newborn had latencies in excess of $200 \mathrm{~ms}$ (Fig. 5).

\section{Response properties}

In light of the differences between the newborn and the adult in terms of latencies and receptive field sizes, it was surprising to note that the response properties of SC neurons in the newborn very closely resembled those found in the adult (Table 1). In both newborns (37/42 or 88\%) and adults (41/ 50 or $82 \%$ ), the vast majority of superficial SC neurons had receptive fields with suppressive regions bordering their excitatory receptive fields. This was evident from the observation that the response to a stimulus within the excitatory borders of the receptive field was degraded significantly when the 


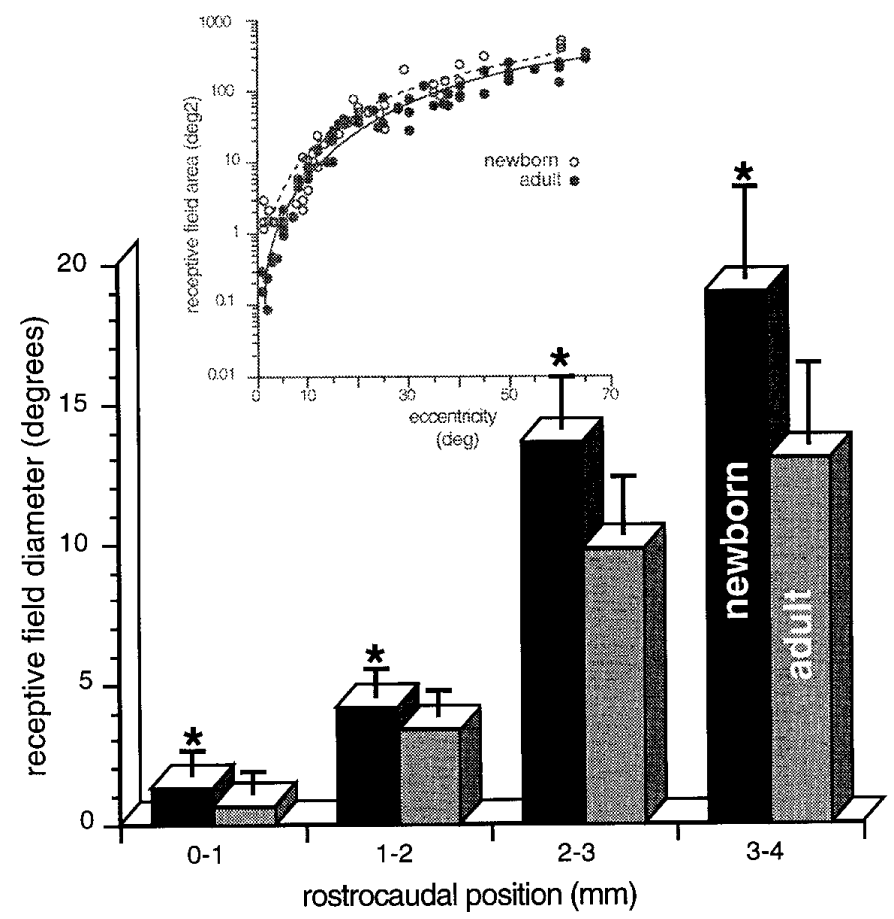

FIG. 4. Receptive fields in both the newborn and adult show a comparable growth in size with increasing retinal eccentricity. Although newborn receptive fields are, on average, $31 \%$ larger than adult receptive fields, there was no significant difference in this enlargement at different eccentricities. Inset: $\log -\log$ plot of these values. Although a trend toward convergence (foveal receptive fields being proportionately larger than more temporal receptive fields) can be seen, the slopes of the 2 lines were not significantly different (F test, $P>0.05$ ).

region outside these borders was stimulated simultaneously. Two stimulation paradigms were employed. In the first, the response to a bar of light within the excitatory borders was compared with that evoked when the stimulus was extended so that it encroached on the area beyond the borders of the excitatory receptive field. In the second, a stimulus presented within the excitatory receptive field was paired with an identical stimulus presented outside the receptive field (Fig. 6). In several cases, the inhibition generated by activating the region outside the excitatory receptive field was powerful enough to suppress completely the neuron's responses to the stimulus within the receptive field.

In both newborn and adult SC neurons, the size of the stimulus in relation to the size of the receptive field played a significant role in determining the magnitude of the neuron's response. In general, a minimum stimulus size (usually 10$20 \%$ of the receptive field diameter) was required to evoke a reliable response. In many neurons, as the size of the stimulus increased to $50-70 \%$ of the receptive field diameter, a monotonic increase in the magnitude of the response was seen (Fig. 7). Often, further increases in stimulus size resulted in a decline in response magnitude (Fig. 7). The ability of neurons to exhibit such within-field spatial summation and spatial inhibition did not increase with development. Indeed, the incidence of neurons with such capabilities were higher in the population of neonatal neurons sampled than in the adult population (see Table 1).

Newborn and adult SC neurons also had very similar ocular dominance distributions. Of the neurons sampled within

the region of binocular overlap (newborn: $n=40$; adult: $n=46$ ), a majority (newborn: $n=33$ or $83 \%$; adult: $n=$ 32 or $70 \%$ ) were activated more vigorously by the contralateral eye (Fig. 8).

Neurons in the SC of newborns and adults responded well to stationary flashed stimuli (Table 1). However, both populations were activated far more vigorously by moving stimuli. Similarly, neurons in both populations were characterized by having little selectivity for stimulus shape, orientation, or direction of movement (Table 1), and exhibited substantially the same preferences for stimulus speed (Fig. 9). Thus the largest component of both populations responded best to stimuli moved at high speeds (i.e., 100 to $>500^{\circ} / \mathrm{s}$ ) ( see Fig. 9); proportionately fewer neurons responded best to intermediate $\left(10-100^{\circ} / \mathrm{s}\right)$ and slow $\left(<10^{\circ} / \mathrm{s}\right)$ stimulus speeds, and the smallest group showed no obvious preference for stimulus speed (i.e., broadly tuned).

\section{DIS C US SION}

Visual responses in the superficial layers of the newborn monkey SC were found to resemble closely those found in

\section{newborn}
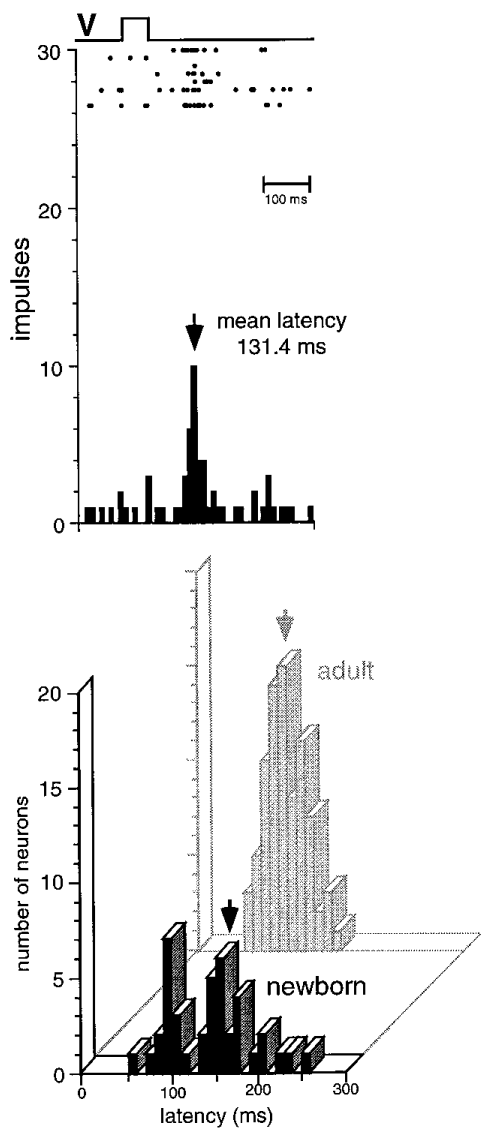

FIG. 5. Visual response latency is significantly longer in the newborn animal than in the adult. Top: representative examples of responses in the newborn (left) and adult (right) to the same flashed visual stimulus (depicted by the square wave above the raster). Both neurons were located in stratum griseum superficiale. Bottom left: population histograms showing the mean latency for neurons in the newborn and adult animals are presented. $\downarrow$, population means (newborn $=159.9 \mathrm{~ms}$; adult $=87.5 \mathrm{~ms}$ ). Bottom right: bar graph shows the mean latencies for all recorded neurons. $* * P<0.01$. 
TABLE 1. Response properties in newborn and adult superficial SC neurons

\begin{tabular}{|c|c|c|c|c|c|c|c|}
\hline & $\begin{array}{l}\text { Direction } \\
\text { Selectivity }\end{array}$ & $\begin{array}{l}\text { Response } \\
\text { to Flash }\end{array}$ & $\begin{array}{l}\text { Surround } \\
\text { Inhibition }\end{array}$ & $\begin{array}{c}\text { Spatial } \\
\text { Summation }\end{array}$ & $\begin{array}{c}\text { Spatial } \\
\text { Inhibition }\end{array}$ & Orientation & Habituation \\
\hline Newborn & $\begin{array}{c}3 / 45 \\
(7)\end{array}$ & $\begin{array}{c}37 / 47 \\
(79)\end{array}$ & $\begin{array}{c}37 / 42 \\
(88)\end{array}$ & $\begin{array}{c}22 / 44 \\
(50)\end{array}$ & $\begin{array}{c}28 / 45 \\
(62)\end{array}$ & $\begin{array}{l}1 / 29 \\
(3)\end{array}$ & $\begin{array}{c}30 / 47 \\
(64)\end{array}$ \\
\hline Adult & $\begin{array}{l}3 / 60 \\
(5)\end{array}$ & $\begin{array}{c}41 / 61 \\
(67)\end{array}$ & $\begin{array}{c}41 / 50 \\
(82)\end{array}$ & $\begin{array}{c}47 / 61 \\
(77)\end{array}$ & $\begin{array}{c}22 / 58 \\
(38)\end{array}$ & $\begin{array}{c}0 / 61 \\
(0)\end{array}$ & $\begin{array}{l}6 / 43 \\
(14)\end{array}$ \\
\hline
\end{tabular}

Parenthetical values are percentages. SC, superior colliculus.

the mature animal. Thus vigorous responses could be elicited from neurons at all sites sampled along the rostral-caudal and medial-lateral axes of the structure, and there was no indication that the incidence of visually responsive neurons was lower in the newborn than in the adult. Furthermore, there were none of the substantial regional differences in the responsivity or selectivity of neurons in the newborn monkey SC that would help to explain the attentive and orientation preferences of human neonates for temporal visual stimuli (Lewis and Maurer 1992; Lewis et al. 1985).
NEWBORN
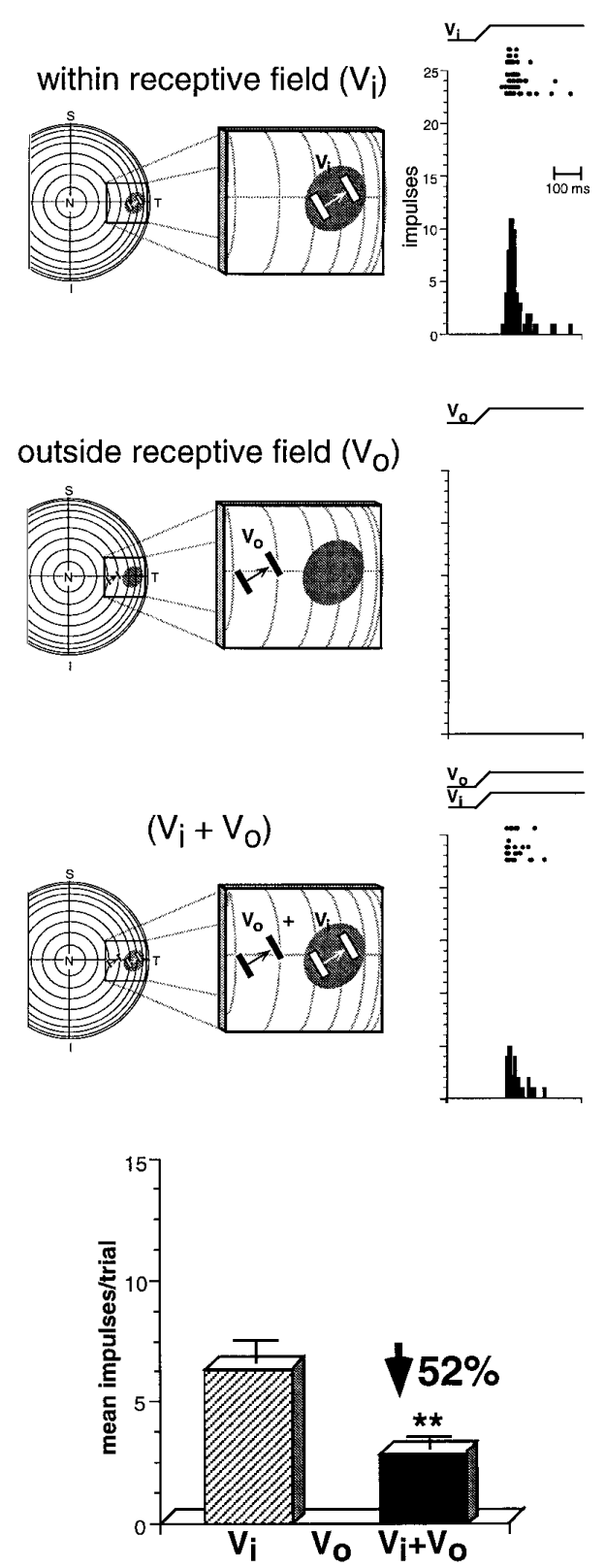

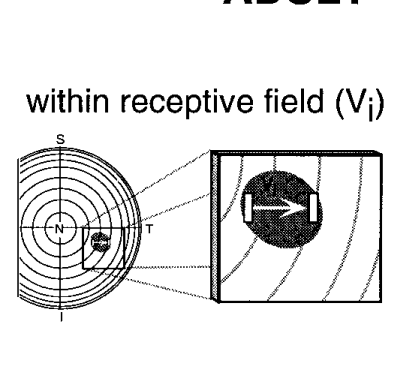

\section{ADULT}
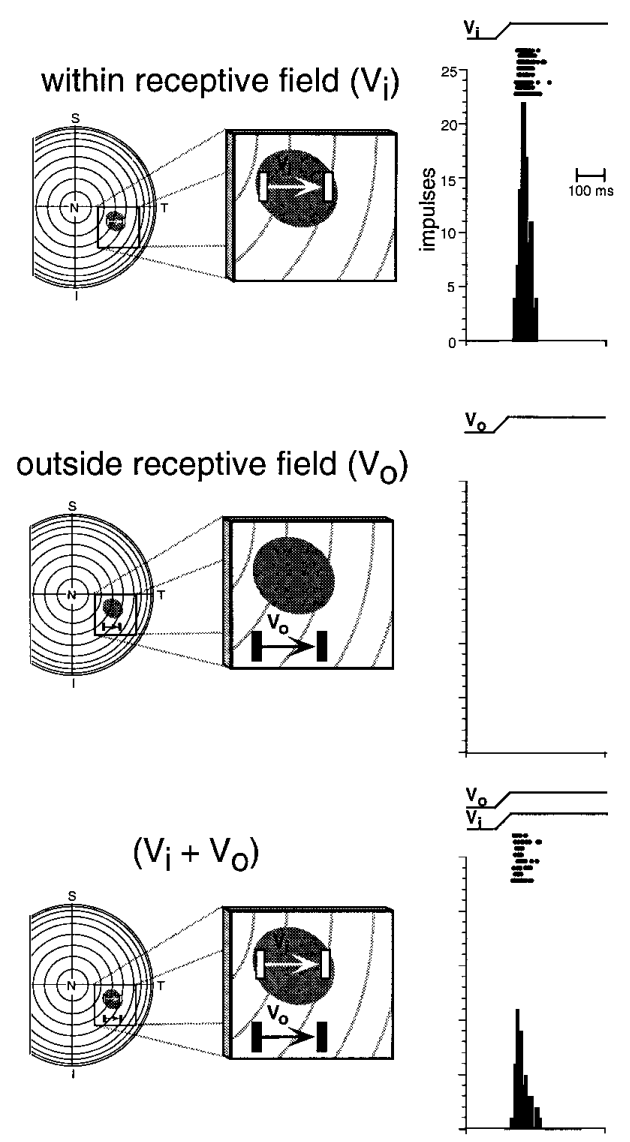

FIG. 6. Regardless of age, most SC neurons exhibit strong surround inhibition. Top: receptive fields (shading), stimuli (bars moving in direction of arrows), and rasters and peristimulus time histograms showing the responses of 1 neuron in the newborn and 1 in the adult to the same 3 stimulus conditions: stimulus within the receptive field $\left(\mathrm{V}_{\mathrm{i}}\right)$, stimulus outside the receptive field $\left(\mathrm{V}_{\mathrm{o}}\right)$, and paired stimulation within and outside of the receptive field $\left(\mathrm{V}_{\mathrm{i}}+\mathrm{V}_{\mathrm{o}}\right)$. Bottom: summary bar graphs illustrate the averaged response to each condition for the neonate and the adult and demonstrate the similar degrees of response inhibition seen when the within-field stimulus is paired with one outside the receptive field. Both neurons were recorded in stratum griseum superficiale. $* * P<0.01$ 


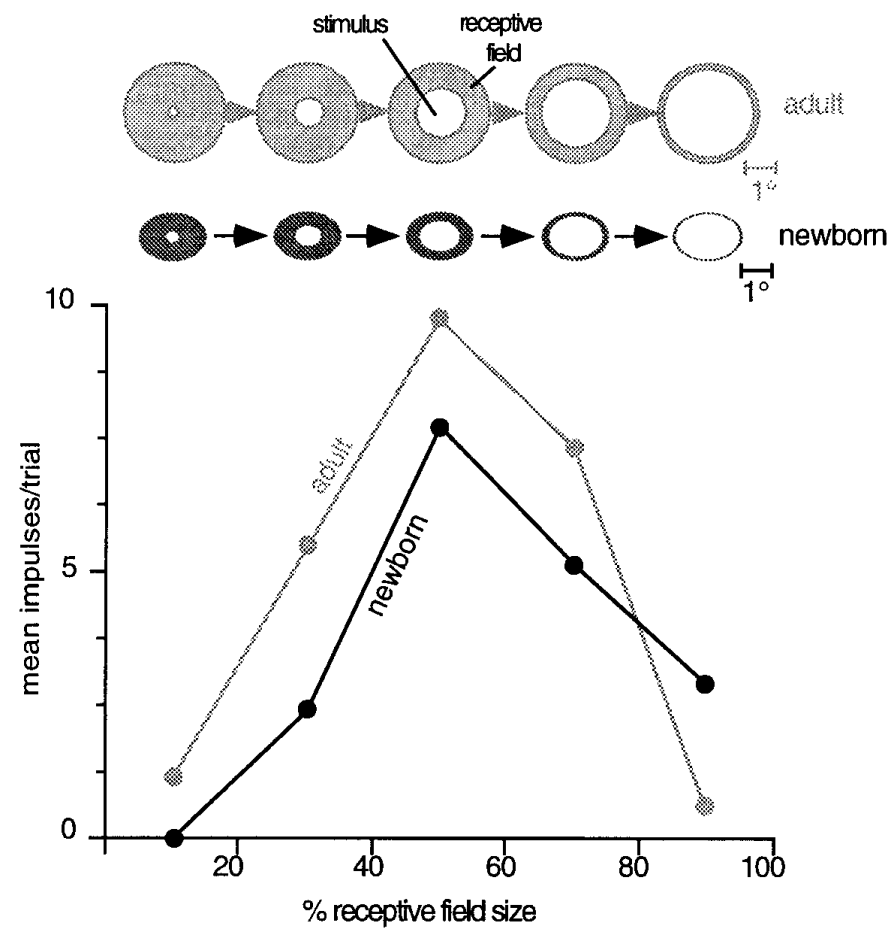

FIG. 7. Many SC neurons exhibit spatial summation and spatial inhibition to stimuli presented within their receptive fields. Averaged neuronal responses are plotted here as a function of relative stimulus size (i.e., proportion of receptive field diameter) for a representative newborn and adult SC neuron. Icons above the graph illustrate stimuli and receptive fields for these 2 neurons with stimuli progressively increasing in size from those that are a small percentage of receptive field diameter (left) to those that nearly encompass the receptive field (right). Note the similarity between the stimulus size/response functions in the newborn and the adult.

The visual receptive fields of newborn SC neurons were well defined and were arranged in an orderly map of contralateral visual space. Although it appeared likely that the entire visual field was functional in the newborn, the absence of sampling in the outermost margins of the structure made it impossible to locate the most eccentric visual receptive fields. The absence of a complete detailed map of visual space in the adult monkey $\mathrm{SC}$ makes it difficult to determine how much further out visual fields might have extended in the adult when compared with the newborn. Nevertheless, the visuotopic organization observed here closely parallels that observed in the adult (Cynader and Berman 1972; Schiller and Koerner 1971; Wallace et al. 1996). As in other mammalian species, the horizontal meridian is represented along the rostrocaudal SC axis and the vertical meridian is represented along the mediolateral axis. Furthermore, the characteristic magnification of foveal and perifoveal space was already evident at birth, with the rostral half of the SC being dedicated to the central $10^{\circ}$ of visual space ( see Stein and Meredith 1993 for a discussion of interspecies comparisons).

Although topographically ordered, receptive fields in the newborn SC were significantly larger than those in the adult. In the adult, receptive fields representing the fovea were typically $<1^{\circ}$ in diameter (Cynader and Berman 1972; Marrocco and Li 1977; Schiller and Koerner 1971; Wallace et al. 1996), but a number of foveal receptive fields in the newborn were two to three times as large. Proportionately, these seemed to be less mature than their more peripheral counterparts (see also Blakemore and Vital-Durand 1981a, for a similar finding in LGN). Nonetheless, peripheral receptive fields were also larger than those found in the adult. Thus, whereas the largest receptive fields in the caudal SC of the adult typically encompassed an area of temporal visual space spanning $\sim 200 \mathrm{deg}^{2}$, comparably positioned receptive fields in the newborn were as large as $500 \mathrm{deg}^{2}$. The presence of proportionately larger receptive fields throughout the visual field in the newborn monkey is consistent with the comparatively low visual acuity of neonatal primates (Atkinson 1984; Dobson and Teller 1978; Norcia and Tyler 1985). The subsequent contraction of receptive fields is likely to reflect the growth of the retina (Rusoff and Durin 1977) and the maturation of GABAergic inhibitory circuits (Mize 1992).

The only other significant difference between newborn and adult visually responsive SC neurons noted here was the substantially longer response latencies in the newborn. These longer latencies are likely to reflect a delayed maturation of retinotectal myelination (Daniels et al. 1978; Moore et al. 1976; Stein 1984; Yakovlev and Lecours 1967) as well as postnatal changes that occur in retinal morphology (Youdelis and Hendrickson 1986). It appears that these changes have little influence on the response properties of these neurons because many of the characteristic receptive field properties of adult SC neurons are already present in the newborn monkey. This is likely in part due to the absence

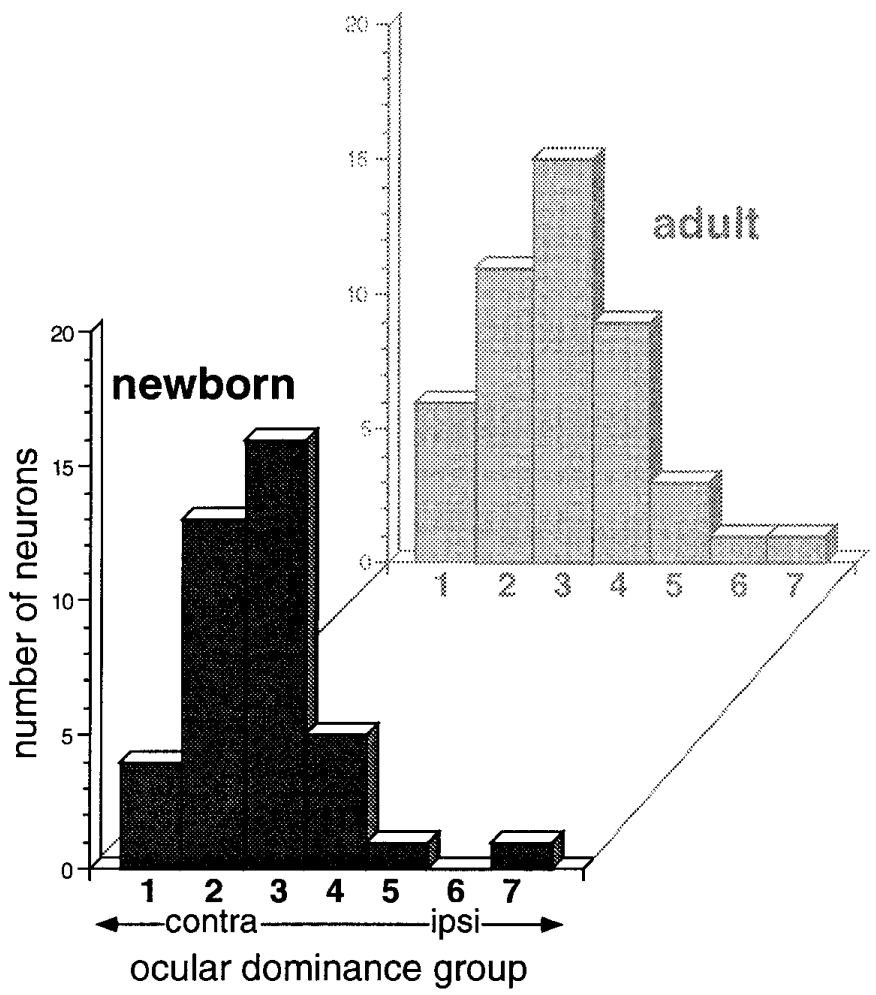

FIG. 8. Neurons in the newborn and adult SC have similar ocular dominance profiles. Standard ocular dominance histograms show a very similar contralateral bias for newborn and adult neurons. In this classification scheme, group 1 represents neurons driven exclusively by the contralateral eye, group 7 represents neurons driven exclusively by the ipsilateral eye, group 4 represents neurons driven equally well by both eyes. 

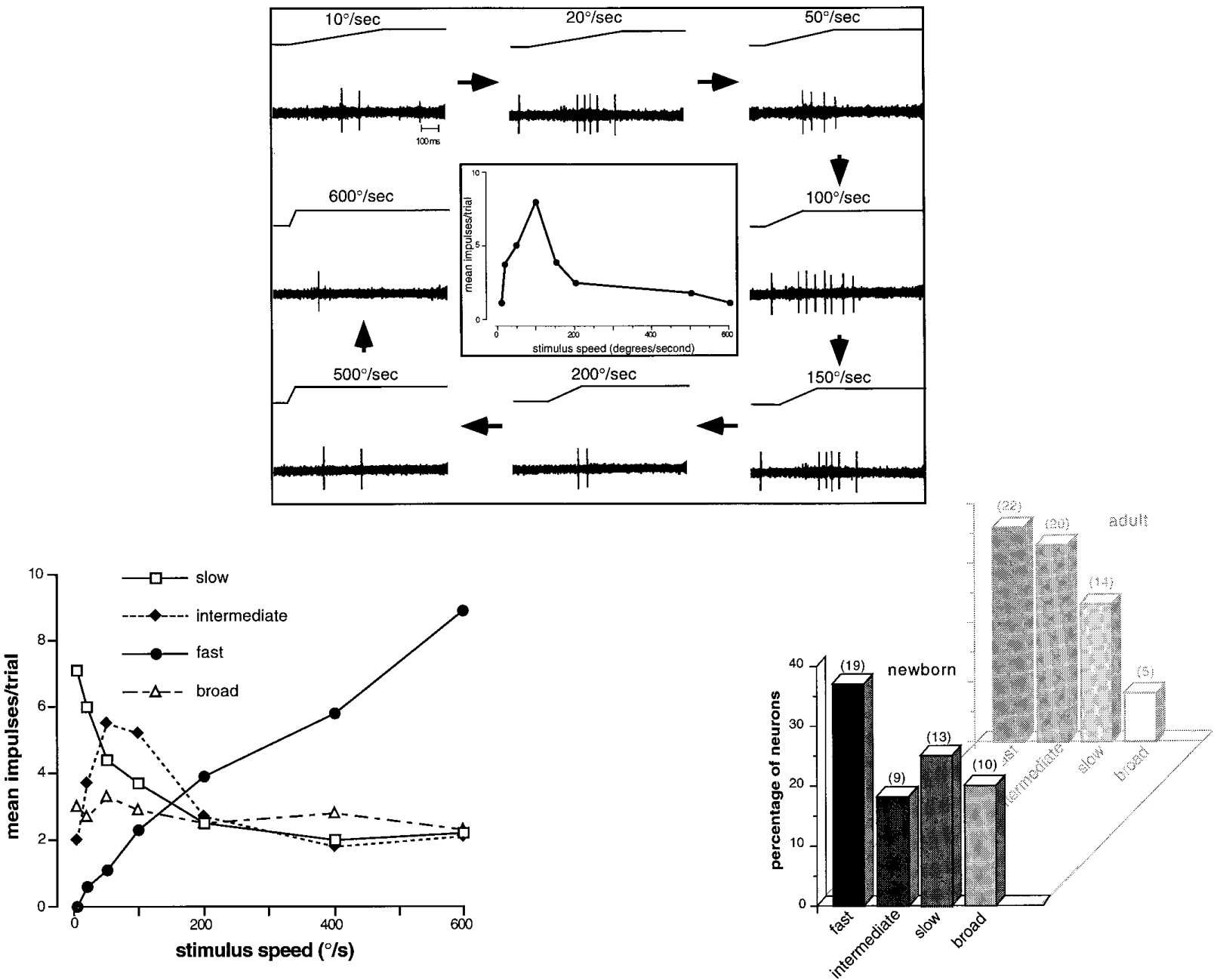

FIG. 9. Newborn and adult SC neurons have similar preferences for stimulus speed. Top: series of oscillographs shows the responses of a neuron in the newborn SC to visual stimuli moving at speeds ranging from 10 to $600^{\circ} / \mathrm{s}$. Middle inset: graph of this neuron's tuning profile. Bottom left: representative tuning curves for 4 neurons in the newborn SC show the characteristic selectivities encountered. Bottom right: bar graphs show that newborn and adult SC neurons have similar population distributions for each of the 4 selectivity categories.

of highly selective properties in the adult animal, as the specific shape, orientation, or direction of stimulus movement are generally not critical determinants of the magnitude of a neuron's response (Albano et al. 1978; Cynader and Berman 1972; Goldberg and Wurtz 1972a; Lane et al. 1973; Marrocco and Li 1977; Moors and Vendrik 1979; Schiller and Koerner 1971; Schiller and Stryker 1972; Updyke 1974; Wallace et al. 1996). Nonetheless, there are two stimulus features to which SC neurons show particular sensitivity: the speed with which the stimulus moves and its size. The selectivity for these features proved to be as well developed in newborns as in adults.

The many similarities observed here between the response properties of visual SC neurons in newborn and adult monkeys suggests that much of the functional maturation of SC neurons takes place prenatally. This is likely to ensure that visual behaviors are possible (albeit not fully mature) immediately after parturition. The advanced developmental state of these neurons at this time is in contrast with the protracted postnatal maturation seen in visually responsive cortical neu- rons (Rodman et al. 1993). Presumably, the complex receptive field properties, and the intrinsic circuitry underlying many higher-order perceptual functions subserved by cortex, require substantially more maturation and/or experience to develop than do those involved in the more immediate behaviors subserved by the SC.

These observations in monkeys differ substantially from those in the more frequently used model of SC development, the cat. When visually responsive neurons are first encountered in the superficial layers of the cat SC (at 6-7 days postnatal), responses cannot be evoked from all sites, and those sites that are active have neurons that are weakly responsive, have exceedingly long latencies, habituate very rapidly, often have poorly defined receptive field borders, and lack the complex response properties that characterize the adult. Even the kinetics of the action potential in neonatal cat SC appear to be immature, with it exhibiting a much longer duration and a more complex wave-shape than in adults (Kao et al. 1994; Stein et al. 1973a). This was not observed in the newborn monkey. 
It is evident that unlike neurons in the cat SC, those in the monkey do not require the extended postnatal maturational period to develop many of the adult-like response properties necessary to subserve visual behaviors (see Stein 1984 for a review). This may reflect not only differences in the length of the gestation period, but also a differential dependence on corticotectal influences. The early responses of superficial layer SC neurons in the cat are presumed to be retinally derived and do not exhibit the complex response properties that characterize the normal adult until corticotectal projections (Stein and Edwards 1979) become functional (Stein and Gallagher 1981). Thus ablation of visual cortex in neonatal cats precludes the maturation of these properties (Berman and Cynader 1976; Flandrin and Jeannerod 1977; Mize and Murphy 1976; Stein and Magalhaes-Castro 1975), and lesioning or deactivating visual cortex in adult cats renders these SC neurons "immature" (Hardy and Stein 1988; Ogasawara et al. 1984; Stein 1978; Stein and Arigbede 1972; Wickelgren and Sterling 1969).

In rhesus monkey, the role of corticotectal projections in superficial layer function is far less impressive. Cortical deactivation increases monocular dominance in SC neurons (Schiller et al. 1974), and lesions that interrupt corticotectal afferents affect their relative motion selectivity (Davidson et al. 1992). Nonetheless, such influences appear to account for only a small complement of these neuron's normal response properties and suggest that visual neurons in the newborn monkey are comparatively more mature than those in the 1- to 3-wk-old cat because they depend primarily on retinotectal influences, which do not change substantially during postnatal maturation except in their conduction velocities.

Recently, observations in behaving adult monkeys have led to the suggestion that the neurons in the superficial layers of the SC are involved in shifts of attention (Robinson and Kertzman 1995). This postulate is consistent with previous findings that a visual stimulus becomes far more effective in activating superficial layer neurons when it is associated with a reward (Goldberg and Wurtz 1972b). It is also consistent with the involvement of these neurons in thalamic circuits (Kaas and Huerta 1988; Luppino et al. 1988) known to play a role in attention (Rafal and Posner 1987). The relative physiological maturity of these neurons in the newborn monkey may indicate that they are already capable of engaging visual attentive mechanisms. If the comparative maturity of the visually responsive neurons examined here reflects the general state of the SC at birth, one also would expect that postnatal experience would not be necessary for many of the cross-modal integrative (Wallace and Stein 1994) and visuomotor (Sparks 1986) functions of the deep $\mathrm{SC}$, thereby confirming early speculation that it is the advanced physiological state of the SC that underlies the impressive sensory and sensorimotor capabilities of neonatal primates (Johnson 1993; Posner 1980).

We thank N. London for technical assistance.

This work was supported by National Institutes of Health Grants EYO6562 and NS-22543.

Address for reprint requests: M. T. Wallace, Dept. of Neurobiology and Anatomy, Bowman Gray School of Medicine/Wake Forest University, Medical Center Blvd., Winston-Salem, NC 27157-1010.

Received 17 April 1997; accepted in final form 24 July 1997.

\section{REFERENCES}

Albano, J. E., Humphrey, A. L., And Norton, T. T. Laminar organization of receptive-field properties in tree shrew superior colliculus. J. Neurophysiol. 41: 1140-1164, 1978.

AtKinson, J. Human development over the first six months of life. A review and a hypothesis. Human Neurobiol. 3: 61-74, 1984.

Berman, N. And Cynader, M. Early versus late visual cortex lesions: effects on receptive fields in cat superior colliculus. Exp. Brain Res. 25: 131-137, 1976.

Blakemore, C. ANd Vital-Durand, F. Postnatal development of the monkey's visual system. In: The Fetus and Independent Life. Basel: CIBA, 1981a, p. $152-171$.

Blakemore, C. AND Vital-Durand, F. Development of contrast sensitivity by neurones in monkey striate cortex. Soc. Neurosci. Abstr. 7: 140, 1981 b.

Boothe, R. G., Dobson, V., And Teller, D. Y. Postnatal development of vision in human and nonhuman primates. Annu. Rev. Neurosci. 8: $495-$ 545, 1985.

Boothe, R. G., Kiorpes, L., Regal, D. M., And Lee, C. P. Development of visual responsiveness in Macaca nemestrina monkeys. Dev. Psychol. 18: $665-670,1982$.

Cynader, M. And Berman, N. Receptive field organization of monkey superior colliculus. J. Neurophysiol. 35: 187-201, 1972.

Daniels, J. D., Pettigrew, J. D., And Norman, J. L. Development of single-neuron responses in kitten's lateral geniculate nucleus. J. Neurophysiol. 41: 1373-1393, 1978 .

Davidson, R. M., Joly, T. J., AND Bender, D. B. Effect of corticotectal tract lesions on relative motion selectivity in the monkey superior colliculus. Exp. Brain Res. 92: 246-258, 1992.

Des Rosiers, M. H., Sakurada, O., Jehle, J., Shinohara, M., Kennedy, C., AND SoKOlOFF, L. Functional plasticity in the immature striate cortex of the monkey shown by the [14C] deoxyglucose method. Science 200: 447-449, 1978.

Dobson, V. AND Teller, D. Y. Visual acuity in human infants: a review and comparison of behavioral and electrophysiological studies. Vision Res. 18: 1469-1483, 1978.

FLANDRIN, J. M. AND JEANNEROD, M. Lack of recovery in collicular neurons from the effects of early deprivation or neonatal cortical lesion in the kitten. Brain Res. 120: 362-366, 1977.

Goldberg, M. E. And Wurtz, R. H. Activity of superior colliculus in behaving monkey. I. Visual receptive fields of single neurons. J. Neurophysiol. 35: 542-559, 1972a.

GoldBerg, M. E. AND Wurtz, R. H. Activity of superior colliculus in behaving monkey. II. Effect of attention on neuronal responses. J. Neurophysiol. 35: 560-574, $1972 \mathrm{~b}$.

Grobstein, P. AND CHOw, K. L. Receptive field organization in mammalian cortex: the role of individual experience in development; In Studies on Development of Behavior and the Nervous System, edited by G. Gottlieb. New York: Academic, 1976, vol. 3, p. 155-195.

HaRdy, S. C. AND STEIN, B. E. Small lateral suprasylvian cortex lesions produce visual neglect and decreased visual activity in the superior colliculus. J. Comp. Neurol. 274: 527-542, 1988.

Horton, J. C. AND Hocking, D. R. An adult-like pattern of ocular dominance columns in striate cortex of newborn monkeys prior to visual experience. J. Neurosci. 16: 1791-1807, 1996.

Hubel, D. H. AND Wiesel, T. N. Receptive fields and functional architecture of monkey striate cortex. J. Physiol. (Lond.) 195: 215-243, 1968.

Hubel, D. H., Wiesel, T. N., And LeVay, S. Plasticity of ocular dominance columns in monkey striate cortex. Philos. Trans. R. Soc. Lond. B Biol. Sci. 278: 377-409, 1977.

JoHnson, M. H. Cortical maturation and the development of visual attention in early infancy. In: Brain Development and Cognition, edited by M. H. Johnson. Oxford: Blackwell, 1993, p. 167-194.

KAAS, J. H. AND HuERTA, M. F. The subcortical visual system of primates. Comp. Primate Biol. 4: 327-391, 1988.

Kao, C.-Q., McHaffie, J. G., Meredith, M. A., and Stein, B. E. Functional development of a central visual map in cat. J. Neurophysiol. 72: 266-272, 1994.

KIORPES, L. AND KIPER, D. C. Development of contrast sensitivity across the visual field in macaque monkeys (Macaca nemestrina). Vision Res. 36: 239-247, 1996.

Lane, R. H., Allman, J. M., KaAs, J. H., and Miezin, F. M. The visuotopic organization of the superior colliculus of the owl monkey (Aotus trivirgatus) and the bush baby (Galago senegalensis). Brain Res. 60: 335-349, 1973. 
LeVAy, S., Wiesel, T., AND Hubel, D. The development of ocular dominance columns in normal and visually deprived monkeys. J. Comp. Neurol. 19: 1-51, 1980

Lewis, T. L. AND MAURER, D. The development of the temporal and nasal visual fields during infancy. Vision Res. 32: 903-911, 1992.

Lewis, T. L., Maurer, D., AND BlackBurn, K. The development of young infants' ability to detect stimuli in the nasal visual field. Vision Res. 25 943-950, 1985.

LupPino, G., Matelli, M., Carey, R. G., FitzPatrick, D., AND Diamond, I. T. New view of the organization of the pulvinar nucleus in Tupaia as revealed by tectopulvinar and pulvinar-cortical projections. J. Comp. Neurol. 273: 67-86, 1988.

MARROCCO, R. T. AND LI, R. H. Monkey superior colliculus: properties of single cells and their afferent inputs. J. Neurophysiol. 40: 844-860, 1977.

McHAfFie, J. G. And Stein, B. E. A chronic headholder minimizing facial obstructions. Brain Res. Bull. 10: 859-860, 1983.

Mendelson, M. J. Visual and social responses in infant rhesus monkeys. Am. J. Primatol. 3: 333-340, 1982.

Meredith, M. A. And Stein, B. E. The visuotopic component of the multisensory map in the deep laminae of the cat superior colliculus. J. Neurosci. 10: 3727-3742, 1990.

Mitchell, D. E. And Timney, B. Postnatal development of function in the mammalian visual system. In: Handbook of Physiology. The Nervous System. Sensory Processes. Washington, DC: Am. Physiol. Soc., 1984, sect. 1 , vol. III, p. 507-555.

Mize, R. R. The organization of GABAergic neurons in the mammalian superior colliculus. Prog. Brain Res. 90: 219-248, 1992.

Mize, R. R. AND MurPhy, E. H. Alterations in receptive field properties of superior colliculus cells produced by visual cortex ablation in infant and adult cats. J. Comp. Neurol. 168: 393-424, 1976.

MoORE, C. L., KALIL, R., AND Richards, W. Development of myelination in optic tract of the cat. J. Comp. Neurol. 165: 125-136, 1976.

MoORS, J. AND VENDRIK, A.J.H. Responses of single units in the monkey superior colliculus to stationary flashing stimuli. Exp. Brain Res. 35: 349-369, 1979.

Movshon, J. A. And Van Sluyters, R. C. Visual neural development. Annu. Rev. Psychol. 32: 477-522, 1981.

Norcia, A. M. AND TyLER, C. W. Spatial frequency sweep VEP: visual acuity in the first year of life. Vision Res. 25: 1399-1408, 1985.

Ogasamara, K., McHaffie, J. G., and Stein, B. E. Two corticotectal systems in the cat. J. Neurophysiol. 52: 1226-1245, 1984.

Posner, M. Orienting of attention. Q. J. Exp. Psychol. 32: 3-25, 1980.

Purves, D. and LaMantia, A. Development of blobs in the visual cortex of macaques. J. Comp. Neurol. 334: 169-175, 1993.

RAFAL, R. D. AND PosNer, M. I. Deficits in human spatial attention following thalamic lesions. Proc. Natl. Acad. Sci. USA 84: 7349-7353, 1987.

RAKIC, P. Prenatal development of the visual system in rhesus monkey. Trans. R. Soc. Lond. 278: 245-260, 1977.

Robinson, D. L. AND KeRTZMAn, C. Covert orienting of attention in macaques. III. Contributions of the superior colliculus. J. Neurophysiol. 74: 713-721, 1995.

Rodman, H. R., O'Scalaidhe, S. P., AND Gross, C. G. Response properties of neurons in temporal cortical visual areas of infant monkeys. J. Neurophysiol. 70: 1115-1136, 1993.

Rusoff, A. C. AND DuRIN, M. W. Development of receptive-field properties of retinal ganglion cells in kittens. J. Neurophysiol. 40: 1188-1198, 1977.

Schiller, P. H. And Koerner, F. Discharge characteristics of single units in superior colliculus of the alert rhesus monkey. J. Neurophysiol. 34: 920-936, 1971.

SCHILLER, P. H. AND STRYKER, M. Single-unit recording and stimulation in superior colliculus of the alert rhesus monkey. J. Neurophysiol. 35: 915924, 1972.

Schiller, P. H., Stryker, M., Cynader, M., And Berman, M. Response characteristics of single cells in the monkey colliculus following ablation or cooling of visual cortex. J. Neurophysiol. 37: 181-194, 1974.

Sherman, S. M. AND SPEAR, P. D. Organization of visual pathways in normal and visually deprived cats. Physiol. Rev. 62: 738-855, 1982.

SPARKS, D. L. Translation of sensory signals into commands for control of saccadic eye movements: role of the primate superior colliculus. Physiol. Rev. 66: 118-171, 1986.

Sprague, J. M. And Meikle, T. H. The role of the superior colliculus in visually guided behaviour. Exp. Neurol. 11: 115-146, 1965.

STEIN, B. E. Development and organization of multimodal representation in cat superior colliculus. Federation Proc. 37: 2240-2245, 1978.

SteIN, B. E. Development of the superior colliculus. Annu. Rev. Neurosci. 7: $95-125,1984$.

Stein, B. E. AND ARigbede, M. O. A parametric study of movement detection properties of neurons in the cat's superior colliculus. Brain Res. 45: 437-454, 1972.

Stein, B. E. AND Edwards, S. B. Corticotectal and other corticofugal projections in neonatal cat. Brain Res. 161: 399-409, 1979.

Stein, B. E. AND Gallagher, H. L. Maturation of cortical control over superior colliculus cells in cat. Brain Res. 223: 429-435, 1981.

SteIN, B. E., LABOS, E., AND KRUGER, L. Sequence of changes in properties of neurons of superior colliculus of the kitten during maturation. J. Neurophysiol. 36: 667-679, 1973

Stein, B. E. And Magalhaes-Castro, B. Effects of neonatal cortical lesions upon the cat superior colliculus. Brain Res. 83: 480-485, 1975.

Stein, B. E. AND Meredith, M. A. Functional organization of the superior colliculus. In: The Neural Basis of Visual Function, edited by A. G. Leventhal. Hampshire, UK: Macmillan, 1991, p. 85-110.

Stein, B. E. And Meredith, M. A. The Merging of the Senses. Cambridge, MA: MIT Press, 1993

TEEs, R. C. Mammalian perceptual development. In: Studies on Development of Behavior and the Nervous System, edited by G. Gottlieb. New York: Academic, 1976, vol. 3, p. 281-326.

UPDYKE, B. V. Characteristics of unit responses in superior colliculus of the Cebus monkey. J. Neurophysiol. 37: 896-909, 1974.

Van Sluyters, R. C., AtKinson, J., Banks, M. S., Held, R. M., Hoffman, K.-P., AND Shatz, C. J. The development of vision and perception. In: Visual Perception: The Neurophysiological Foundations, edited by L. Spillmann and J. S. Werner. San Diego, CA: Academic, 1990, p. 349379.

Wallace, M. T. AND Stein, B. E. Cross-modal synthesis in the midbrain depends on input from cortex. J. Neurophysiol. 71: 429-432, 1994.

Wallace, M. T., Wilkinson, L. K., AND Stein, B. E. Representation and integration of multiple sensory inputs in primate superior colliculus. $J$. Neurophysiol. 76: 1246-1266, 1996.

Wickelgren, B. G. AND STERLing, P. Effect on the superior colliculus of cortical removal in visually deprived cats. Nature 224: 1032-1033, 1969.

WiESEL, T. N. AND Hubel, D. H. Ordered arrangement of orientation columns in monkeys lacking visual experience. J. Comp. Neurol. 158: $307-$ 318, 1974.

WiLliams, R. AND Boothe, R. Development of optical quality in the infant monkey (Macaca nemestrina). Invest. Ophthalmol. Vis. Sci. 21: $728-$ 736, 1981.

Wurtz, R. H. AND Albano, J. E. Visual-motor function of the primate superior colliculus. Annu. Rev. Neurosci. 3: 189-226, 1980.

YAKOVLEV, P. I. AND LeCOURS, A. The myelogenetic cycles of regional maturation of the brain. In: Regional Development of the Brain in Early Life, edited by A. Minokowski. Philadelphia, PA: Davis, 1967, p. 3-70.

YoudELIS, C. AND HENDRICKSON, A. A qualitative and quantitative analysis of the human fovea during development. Vision Res. 26: 847-855, 1986. 